\title{
Assertive community treatment-Issues from scientific and clinical literature with implications for practice
}

\author{
Alan Rosen, FRANZCP, MB, BS; ${ }^{{ }^{*}}$ Kim T. Mueser, PhD; ${ }^{2}$ Maree Teesson, $\mathbf{P h D}^{\mathbf{3}}$ \\ ${ }^{1}$ Royal North Shore Hospital and Community Mental Health Services, Sydney, New South Wales, Australia; School of \\ Public Health, University of Wollongong, Wollongong, New South Wales, Australia; and Department of Psychological \\ Medicine, University of Sydney, Sydney, New South Wales, Australia; ${ }^{2}$ Department of Psychiatry, Dartmouth Medical \\ School, Hanover, NH, and Dartmouth Psychiatric Research Center, Concord, NH; ${ }^{3}$ National Drug and Alcohol \\ Research Centre, University of New South Wales, Sydney, New South Wales, Australia
}

\begin{abstract}
This review describes Assertive community treatment (ACT), an integral component of the care of persons with severe mental illness. Drawing on research from North America, Australasia, and Britain, we summarize the current evidence base for ACT and examine the trends and issues that may affect practice. Strong evidence supports the fidelity standardization, efficacy, effectiveness, and cost-effectiveness of ACT models in psychiatry. Yet, significant methodological problems and issues affect implementation. The evidence indicates that the ACT model is one of the most effective systematic models for organizing clinical and functional interventions in psychiatry. Effective systems based on the ACT model meet more ACT fidelity criteria; are often noncoercive; do not rely on compulsory orders; may rely on a wider range of interventions than just medication adherence, including vocational and substance abuse rehabilitation; contain other evidence-based interventions and more mobile in vivo interventions; involve individual and team case management; may involve consumers as direct service providers; and have an interdisciplinary workforce and support structure within the team, providing some protection from work-related stress or burnout.
\end{abstract}

Key words: assertive community treatment, case management, evidence based, implications, issues, mental health, mental health treatment, practice, psychosocial rehabilitation, severe mental illness.

\section{INTRODUCTION}

In this review, we describe first how assertive community treatment (ACT) is becoming increasingly integral to the care of individuals with severe mental illness. Then, we briefly review the evidence base for ACT. Finally, we examine the trends and issues arising from research on case management that have important implications for clinical practice.

Major changes have occurred over the last four decades in the delivery of psychiatric care, especially to people with severe and persistent mental illnesses such as schizophrenia, bipolar disorder, and treatment-refractory depression. Before the deinstitutionalization movement of the 1960s and 1970s, the vast majority of individuals with persistent mental illness spent most of their lives in psychiatric

\footnotetext{
Abbreviations: ACT $=$ assertive community treatment, DACTS $=$ Dartmouth Assertive Community Treatment Scale, IPS = individual placement and support, LSP = Life Skills Profile, $\mathrm{RCT}=$ randomized controlled trial.

*Address all correspondence to Alan Rosen, FRANZCP, MB, BS; Royal North Shore Hospital and Community Mental Health Services, 24 Olga Street, Sydney, New South Wales, Australia 2067; 61-2-94483266; fax: 61-2-94483277. Email: arosen@nsccahs.health.nsw.gov.au

DOI: 10.1682/JRRD.2006.09.0110
} 
hospitals, where determining and addressing their clinical and living needs and coordinating basic service provision were easy. As the locus of care shifted from the hospital to the community, mental health services became less accessible and more fragmented, with many individuals unable to navigate the increasingly complex system to meet their needs [1]. Case management was developed to solve to this problem by assigning the assessment of consumers' needs and coordination of their treatment to a specific member of the service system. After the need for case management was articulated, some form of case management became standard in the treatment of severe mental illness throughout the Western World.

"Case management" is not a unitary concept in mental health treatment. Rather, it refers to a heterogeneous range of methods applied in mental health, as well as other health welfare and service sectors. In the mental health service context, case management is defined as the role of combining into one coherent system all services required to meet the consumer's needs, usually while he or she is living in the community but also during temporary hospitalization periods [2].

Contemporary mental health services use several models of case management, such as the brokerage, clinical, strengths, rehabilitation, and ACT models [3-5]. Historically, the brokerage approach to case management was staffed by minimally trained individuals who assumed a relatively sedentary, passive response to helping consumers meet their needs. Over time, brokerage models gradually yielded to clinical case-management approaches in which more thoroughly trained professionals actively anticipate and respond to consumers' needs.

Earlier study of community alternatives to hospitalbased care showed that they were only moderately effective in the long term for high-intensity service users with severe and prolonged mental illnesses. This result was particularly true when case loads remained high or the intensity of the team effort could only be sustained during crises [6]. The ACT model was specifically developed to address these consumers' needs by provision of more intensive community services by clinical treatment teams that assume 24-hour responsibility for consumers' treatment [6]. The effectiveness of ACT was evaluated with a randomized controlled trial (RCT) [6] and subsequent replications [7], which demonstrated fewer hospitalizations and days in the hospital, greater stability in the community, and improved quality of life [2]. ACT is the most researched case-management model and, as such, is the focus of this review.

\section{STATUS OF EVIDENCE}

We will address four topics related to evaluating the evidence supporting case-management models, particularly ACT [8]: (1) a clear definition of case management (2) the efficacy of case management, (3) the effectiveness of case management, and (4) the cost-effectiveness of case management.

\section{Accurately Defining Case Management}

Given such diverse models, how can we operationally define case management? In the research literature, ACT is the most well-defined and studied form of case management. While some authors distinguish ACT from other case-management models [9-10], others in the field conceptualize case-management systems as providing diverse services to consumers, including ACT services to those consumers who most need them [2]. Thus, some case-management systems can be conceived of as serial dilutions of the ACT model, with service intensity titrated to consumers' individual and changing needs. From this perspective, one can argue that Stein's [9] differentiation of ACT from other case-management approaches mainly illustrated the ineffectiveness of traditional brokerage case-management models for treating individuals with severe mental illness.

Several books and guidelines have standardized ACT practice [11-13]. ACT teams usually include professionally skilled interdisciplinary members with a 1:10 or less case manager:consumer ratio and assume full responsibility for consumers in and out of office hours. ACT team members can respond to crises and are adept at psychosocial interventions, as well as at coordinating physical and pharmacological interventions, including substance use disorder treatment and vocational rehabilitation services. To provide services to the consumers who need them most, ACT teams emphasize providing most services in the community rather than the clinic $[7,14]$.

The principles of ACT have been codified in the 28item Dartmouth Assertive Community Treatment Scale (DACTS), a scale designed to measure fidelity to the ACT model [2,15-16]. Fidelity scales are important for demonstrating that an intervention has been implemented according to the defining principles of the program. Over 
multiple research studies, fidelity scales such as the DACTS may potentially clarify which intervention components are most critical to improved outcomes. However, the relative importance of the different DACTS component items is presently unknown and a key issue for future research.

\section{Efficacy}

The evidence for the efficacy of ACT is strong. Mueser et al.'s review of RCTs, both quasiexperimental and pre/post designs, found that compared with "usual mental health care," ACT teams increased and maintained contact with care, decreased use of hospital-based mental health care, improved consumer outcomes (including quality of life), reduced symptoms experienced, and increased housing stability [5]. The Cochrane review of ACT reached similar conclusions [10], as did Bond et al.'s review of 25 RCTs [17]. ACT also is usually found to promote high consumer and family satisfaction [18], and outcomes are generally better when fidelity to the original intervention is greater $[17,19]$. Dixon's review concluded that reduced hospital days is the most consistent finding of efficacy studies, while reduced rehospitalizations; gains in functional status, including employment and social skills; and medication compliance are less consistent but frequently reported findings [19]. For outcomes like housing stability, time in jail, and substance abuse, roughly half of studies demonstrate an improvement with ACT, while the others show no significant difference [20].

\section{Effectiveness}

Another challenge is demonstrating that casemanagement interventions are useful when applied to routine clinical settings. Funding and motivation are usually high in research studies [21], and these do not easily generalize to nonresearch settings. However, many of the RCTs of ACT have been conducted in real-world settings. At this level of effectiveness, the outcomes have been mostly positive. Thus, the important issues for ACT do not lie in the efficacy/effectiveness debate. Rather, they revolve around changes in service systems since the 1970 s $^{*}$ and studies comparing these changes with previously standard systems (e.g., the shift from long-term

* Dr. Gary Bond, personal communication, 2006. psychiatric hospitalization to more community-based services with briefer hospital admissions).

In reviewing the evidence for ACT effectiveness, Morse and McKasson concluded that margins of better outcome for ACT were limited by the degree to which ACT intervention adhered to fidelity criteria and to which comparison services improved and increasingly offered key ACT features [22]. Teesson and Hambridge demonstrated that ACT with Australian homeless populations may improve functional outcomes and housing stability long before any substantial decrease in hospital use [23]. In this study, hospital admissions rose initially, probably because they could better locate people in exacerbation. However, from years 2-4, admissions significantly decreased [24] to levels similar to those found in a study of ACT with a suburban contemporary comparison group over the first year of follow-up [25].

Another Australian study demonstrated in a national survey that the odds of hospitalization for individuals with severe mental illnesses almost tripled (odds ratio $=$ 2.95, confidence interval $=1.94-4.47$ ) for those without a case manager and that a case manager was the most important modifiable factor in determining hospitalization [26]. This finding should hold also for ACT, among other models of case management.

\section{Cost-Effectiveness}

Most economic analyses have found that ACT reduces treatment costs compared with standard casemanagement approaches. This reduction has been largely attributed to reduced hospital bed days [17,27]. The Cochrane (United Kingdom) review of ACT concluded that "ACT if correctly targeted to high users of inpatient care, can substantially reduce the costs of hospital care whilst improving outcome and patient satisfaction" [10].

Latimer found that higher fidelity programs reduced hospital days 23 percent more than lower fidelity programs [27]. But, he cautioned that as mental health systems rely less on hospitals over time, the cost advantages of ACT will be harder to achieve and justification for the model will need to be based more on its clinical benefits. The Lewin Group considers it a limitation that many studies targeted consumers who had high inpatient use rates before the ACT intervention [20], but many countries still have a high need to seek less restrictive alternatives with better outcomes for these individuals. On the other hand, this review also concluded that cost savings as a result of ACT would be better demonstrated if indirect costs were 
included, such as all health welfare and societal costs, plus recurrent and capital opportunity costs, including the costs of buildings and land.

\section{ISSUES FROM EVIDENCE BASE AND CLINICAL LITERATURE WITH IMPLICATIONS FOR PRACTICE}

\section{What Makes Assertive Community Treatment Work?}

This section addresses whether case management is more effective when intensity of contact is greater or whether other quality of care or content factors are equally or more important; most of the evidence comes from ACT or diverse "intensive case management" studies. These factors include having more intensive opportunities to apply a range of psychosocial interventions, e.g., medication adherence, psychological therapies, family interventions and employment; and concurrently providing specific interventions for special populations, e.g., consumers with early psychosis, consumers with comorbid substance abuse or sensory disorders, or consumers who are homeless. In particular, we will discuss medication adherence and vocational interventions when applied concurrently with ACT.

\section{Intensity Versus Content of Intervention in Determining Outcome}

Further analysis of an Australian RCT of ACT [28] examined which factors were related to outcome [2]. The study demonstrated that consumers who received ACT compared with standard case management showed improved social functioning, had fewer admissions involving police, and were more likely to engage and stay in treatment. Interestingly, intensity of contact alone was unrelated to the positive outcomes achieved, implying that not only the intensity of the intervention was important for outcome but also the quality of the intervention. This finding is consistent with that of Burns et al. [29], who reported the results of a large RCT of intensive case management and standard care in which the main difference between groups was case load. They found that a decline in case load alone did not improve outcome. They argued that mental health planners may need to attend more to the content of treatment rather than to changes in service organization alone.

Such content arguably should include routine use of evidence-based psychosocial interventions such as family intervention [30], vocational and cognitive-behavioral strategies [31], plus adequate in-service training and outcome-based supervision [32]. Ryan et al. examined the patterns of service delivered to individuals with severe and persistent mental illness over their first year of intensive case management [33]. Consumers had better outcomes when case management focused on family, housing, and community support services. McFarlane established that ACT and multiple family groups synergistically improved outcomes in schizophrenia [30].

\section{Medication Adherence}

Medication monitoring is a key feature of ACT, though the evidence base has not yet determined whether this is a "critical ingredient." Surprisingly few studies have assessed medication adherence [18], largely because it is difficult to assess accurately [34]. This lack of research is a concern since some critiques of ACT ascribe the positive outcomes to this factor. The issue of improved medication adherence for ACT teams may not be a methodological issue as much as an important and unaddressed question regarding how ACT works. That is, medication monitoring and delivery in vivo are core features of ACT programs, and the major effects of ACT are on hospitalization (with more moderate effects on symptoms), the very same outcomes affected by medication.

A very reasonable question about how ACT works is whether some, most, or all of the major effects of ACT are attributable to its medication-monitoring feature. Addressing this question is difficult, partly because it would involve performing "dismantling” studies to evaluate particular component mechanisms, whereas most mental health service researchers study packages of interventions without systematically teasing apart the impact of their components. However, this issue is worth pursuing because the implications are important and suggest that the major reason some providers want to implement ACT could be addressed more economically in some settings by alternative medication delivery systems. Some programs already use these, as in Connecticut, where visiting nurses monitor medications, or in Wollongong, Australia, where training is being widely implemented in cognitive-behavioral medication adherence strategies, e.g., motivational interviewing. Also, a more general literature demonstrates that medication adherence increases with engagement in a therapeutic alliance or development of a therapeutic relationship [35-36], but this is beyond the scope of this article. 


\section{Special Populations and Needs}

This section discusses ACT combined with "add-on" models, in which a concurrent intervention is integrated into the work of the ACT team to meet specific needs.

Important adaptations exist for using ACT with special problem populations such as people with severe mental illness who are also dually diagnosed with substance abuse [37] and/or early psychosis [38], are homeless [39-40], or have brain or sensory impairment, e.g., deafness. However, insufficient research supports their effectiveness as yet [18].

In the recent past, some evidence suggested that adaptations of ACT held promise for vocational rehabilitation. By putting the clinician in the community, alongside the person being treated, much more focused intervention could occur in and around potential and actual workplaces. Consistent evidence exists that ACT is a reliable vehicle for delivering vocational interventions and achieving truly competitive employment in this population [41-44]. Two major studies, one with a matched comparison group [45] and the other a rural study with a randomized control group [46], demonstrated superior outcomes for ACT integrated with individual placement and support (IPS) vocational intervention. Such integration usually entails meeting the fidelity criterion by "embedding" at least two vocational specialists as regular members of the ACT team.

These findings support integrating vocational and ACT clinical services at the program level rather than as case-management services operating separately from vocational services, as in the traditional vocational rehabilitation vendor model [47]. IPS is not so much an adaptation of ACT as a service that can be added to customary ACT services. While they are clearly synergistic models, each can be implemented in various different configurations and settings and each has its own substantial evidence base.

\section{Who Does Best with Assertive Community Treatment? Issues About Intensity of Case Management for Different Subpopulations}

This section addresses Goldman et al.'s [48] and some administrations' question about whether assertive or intensive case-management models should be implemented for all or most individuals with severe mental illnesses. Would this improve outcomes or be wasteful and deter some people needing more low-key clinical and functional support from seeking services?
First, we should clarify that the developers of ACT have never advocated or intended its use in this way. Second, evidence suggests that the most assertive and intensive forms of case management should be reserved for those individuals with mental illness who have the severest symptoms and disabilities. ACT was developed to address the specific needs of those consumers with severe mental illness who often remained hospitalized for long periods or who had poor or erratic community functioning and could not consistently access or be engaged by community-based services. This consumer subgroup was consequently prone to frequent relapses and rehospitalizations. Applying the ACT approach to all consumers with severe mental illness seems inconsistent with the original intentions of the model, and attempts to apply the model more broadly have not been that successful $[4,49]$.

PRiSM was a large-scale study of case management in practice in Britain [50-51]. It compared case management of persons with schizophrenia in one suburban catchment area in South London with more "intensive" case management in a neighboring catchment. Intensive case management included providing an additional number of case-managing staff to the whole experimental catchment compared with the control catchment. PRiSM demonstrated that the intensive condition had no particular benefit or only weak benefits but cost more.

The PRiSM experimental intervention model purported to be a proxy for ACT, but in fact it demonstrated little fidelity to any well-studied service model. Moreover, PRiSM did not focus on case management of the population in need: it did not select consumers with more severe mental illness for more intensive case management, but rather spread its staffing over the entire consumer base, including some people without one measurably active symptom (25\%), problematic behavior or disability (33\%), or any history of hospital admissions [52]. The experimental-sector team had much less experienced clinical leadership and staff and less say over which individuals were admitted than the control-sector team. In brief, the study showed that just throwing extra resources at an underdeveloped mental health service in a relatively unfocused fashion is not particularly effective.

The Robert Wood Johnson Foundation multicity study of community mental health service provision likewise concluded that the most intensive case-management services should be reserved for and focused on those individuals with the most severe disabilities; that is, "one size does not fit all” [48]. We can conclude that deploying 
ACT or other intensive case-management models for all individuals with a severe mental illness diagnosis but no or few current disabilities is unlikely to improve outcomes. Implementing these services for individuals who have achieved substantial levels of autonomy, recovery, and insight would also be wasteful and expensive and could even deter them from seeking or maintaining contact with other more appropriate, less-intensive services.

\section{Coercion and Control Variables Deployed in Association with Case Management}

This section addresses the application or restriction of coercion, paternalistic practices, and legal control orders in association with case management and the effects of such practices, if applied.

\section{Coercion and Paternalism}

While most service users do not perceive ACT as coercive [53], occasional issues around coercion persist, largely unsupported by data. ACT has been suggested to be too coercive and paternalistic because it induces dependency, applies financial control by becoming the consumer's "financial payee," pressures the consumer to take medication, and generally "case manages" consumers "to death," implying a higher suicide rate (although this is contrary to most evidence) [54-56]. In reply, Test and Stein stated that coercion is not part of the model and those programs calling themselves ACT that use coercion should modify their practices [56]. Indeed, ACT was designed to provide individuals with severely disabling mental illnesses adequate support and assistance so that they could live freely in the community and improve their quality of life.

Solomon summarizes evidence demonstrating that coercive practices do not prevail in ACT teams, with case managers relying on verbal negotiation rather than coercion and generally using involuntary admissions and other external authorities with less than 5 percent of consumers [18]. This would compare favorably with most community teams working with such populations. Moser's study demonstrates that ACT programs vary in their degree of coercion, as assessed with her set of measures, including the Objective Measure of Agency Control, practitioner self-report, and independent ACT trainer rating scales of restrictive practices [57]. Her main findings were that lower quality clinical practices (e.g., assessment and treatment planning) and practitioner paternalistic and pessimistic attitudes were most associ- ated with use of restrictive practices. Neither consumer characteristics nor level of ACT fidelity were statistically related to use of restrictive practices or control by ACT teams. Limitations included the small sample size, since the team was the unit of analysis, and that consumers and families did not rate perceived coercion.

Generally, ACT teams use coercive strategies such as legal orders with $<10$ percent of consumers, usually when the consumer has had recent substance abuse problems, a history of arrest(s), or repeated hospitalizations $[53,58]$.

Issues concerning paternalism and the fostering of long-term dependency may stem from the assumption that once consumers are transferred to an ACT team, they will require the same level of service for life. However, several studies demonstrate that stabilized individuals can be transferred to less-intensive services with no adverse consequences [53,59-60].

Far from perceiving ACT as controlling, which is necessary with a small proportion of clientele (e.g., offenders on forensic orders), consumers and families have been more satisfied with this service model then any other intervention [17,53,61]. Consumers valued the team's availability, home visits, the continuity of care from the same providers, and the alliance with accustomed mental health professionals.

\section{Use of Community Commitment Laws to "Aid" Case Management}

An increasing number of Western country jurisdictions are being pressured to change laws to make committing individuals with mental illness for involuntary community treatment easier. A common argument is that this change will improve treatment outcomes for those who now drop out of treatment. In other jurisdictions, outpatient commitment provisions still do not apply. Moser's formulation is that outpatient commitment is an aspect of coercion [57]. However, Diamond demonstrates that such legal coercion will not lead to more effective treatment if the treatment itself is inadequate [62]. The least adequate and most passive psychiatric treatment systems usually rely most on commitment, whether in the hospital or the community. What can be practically coerced in the community is extremely limited (e.g., injectable medication). Outpatient commitment shifts the focus from other treatment and support that may have been accepted voluntarily, and moving from a collaborative to a controlling relationship has major interpersonal costs [62]. This conclusion is 
corroborated by Australian research that demonstrated that the statewide implementation of outpatient commitment or community orders, without ACT systems, did not improve outcomes [63].

In some settings, ACT is being increasingly used for people with severe mental illness and criminal justice involvement (e.g., jail diversion, convicted sex offenders with severe mental illness), so more formal control strategies may be applied.

\section{Case-Management Workforce and Service Systems}

This section discusses concerns about workforce variables such as work-related stress, professional mix and balance, the trend toward employing consumers in recovery as service providers, and the choice between individual and team case-management practices.

\section{Work-Related Stress or Burnout}

Innovations such as ACT [8] have addressed burnout in case managers on interdisciplinary mental health teams with large caseloads by limiting case ratios and sharing case-management responsibility for populations with complex needs. Boyer and Bond found that ACT programs enhanced protection against burnout [64], whereas other earlier studies demonstrated the partially protective effect of full membership on an interdisciplinary team, including its cooperative work and support structure [2,65-66].

\section{Professional Mix and Balance}

Rapp and Goscha concluded that while case manager credentials may be relatively unimportant, interpersonal skills are more critical [67]. Australasian community mental health teams, including ACT teams, favor integration of case managers from all mental health disciplines, including nursing, social work, occupational therapy, and psychology [2]. British teams are often described as having mostly nurses, with "access to" allied professionals and psychiatrists [68]. Case-management systems should avoid professional monocultures while systematizing core multidisciplinary skills to ensure that each professional discipline's distinct contribution is highly valued and integrated and to maintain strong professional support links [66]. Australasian guidelines do not support developing a generic mental health case-manager role [69], either by merging professionals of diverse tertiary training and backgrounds or employing nonprofessional case managers. Interdisciplinary teamwork brings many more up-to-date skills to bear on shared challenges, enhances peer support, and strengthens hybrid vigor while also maximizing professional ethical standards and quality of care [70].

So, while staff should share core skills (including case management), an integrated management system, clinical direction, and team supervision common to all professional disciplines, they should also be encouraged to exercise their distinct professional skills and maintain links with their professional discipline for ethical and professional advice and a significant proportion of their postgraduate learning and professional supervision.

\section{Service Users as Service Providers}

Some policy makers and providers have recognized the possible benefit of integrating consumers as members of teams [22]. Rapp and Goscha [67], reviewing reports of employment of consumers as case managers, ancillary case managers, or case-manager "extenders," conclude that this practice is promising. Consumers may consider that their abilities to engage emotionally and provide support outweigh any lack of formal credentials [67]. In generating principles and tools for shifting ACT from efficacy trials to standard practice, Phillips et al. used an extended version of DACTS and included the criterion that consumers on the ACT team serve as (1) team members, providing direct services as peer specialists, and (2) clinicians (e.g., case managers) with full professional status [53]. They reviewed the pros and cons described in the literature and found that, while personal experience with mental illness may afford these individuals a shared perspective with consumers and generate trust, they may be more vulnerable to stress in the job, have greater difficulty maintaining boundaries, and face stigma from other professionals. Most consumer providers, however, behave as professionally as most health providers, particularly if well supervised and taught carefully about when disclosure is and is not appropriate, etc. They found no data suggesting that consumers should be restricted from filling any position for which they might be qualified, but U.S. third-party payers (health insurers, etc.) are still less likely to pay for services delivered by a peer support specialist than by a consumer filling a recognized professional role.

Some peer support specialists now receive training in recovery-oriented support [71] at the community college level [72]. This training sometimes qualifies them more specifically than some of their team colleagues, who may be high school or nonspecific college-level case managers. 
Lefley reviewed multisite studies that demonstrated that consumer peer-support services and consumer-operated service programs resulted in reduced hospitalization; more effective case-management provision; and increased quality of life, including enhanced independence, employment, social support, and education [73]. More problematic findings included power conflicts and failure of many consumer-run services to achieve their central principle of empowering consumers to gain more control over their lives. This result may be because consumer-run services often tried (often unsuccessfully) or were pressured to replicate services previously provided by the local mental health centers. Consumer-run services were never envisaged to substitute for mental health services or to operate independently and unsupported by seasoned clinicians. Some organizations may see consumer-run services as an inexpensive way to replace professionals when, to be optimally effective, they probably need to work together with complimentary roles.

Davidson et al. reviewed the development and proliferation of peer support in the mental health system, as part of the emerging recovery movement [74]. They also reviewed four RCTs that demonstrated few differences in outcome between conventional care provided by peers versus nonpeers. They concluded that peer support is still in its early development and is a promising, if unproven, practice. However, no rigorous data as yet indicate superior outcomes for including consumer peers on ACT teams [18].

\section{Individual Versus Team Case Management}

Krupa et al. found that consumers value one primary relationship with a team member who listens and understands them [75]. Contrary to earlier, more rigid interpretations of ACT fidelity criteria that required consumers to relate to the whole team rather than any particular staff member, one can argue that individual case coordination, engagement, and advocacy are entirely compatible with team case management $[2,67]$. While shared caseloads may not be a critical ingredient of effective case management, receiving group supervision, meeting frequently for team problem solving of each other's "cases," sharing knowledge of consumers and resources, training, and supporting one another are essential for case managers $[33,67]$. ACT team members must work interdependently in community settings and employ initiative, pragmatism, "street smarts," and the ability to work as a group [53], although being able to engage the consumer one-onone in an ongoing therapeutic alliance may be equally important [35-36]. (Also see section, "Qualitative Evaluation of Consumer-Case Manager Relationship.”)

\section{Concerns About Routine Evaluation of Case-Management Teams}

\section{Can Fidelity Criteria Determine Whether Case-Management Teams Will Be Effective?}

Salyers et al. developed an actuarial method for defining program standards [16] that built on the DACTS and headed toward expectancy-referenced criteria linked to better outcomes, which then led to a brief grading system that clearly discriminated ACT from other forms of case management. European researchers assert that they replicated ACT in Europe without the advantageous outcomes found in North American and Australian studies [76-77], but their purported ACT proxy interventions, e.g., "intensive case management," have been shown to meet far fewer fidelity criteria than most ACT studies [2,78-79].

After criticizing Teague et al.'s DACTS [15] as being too "theoretical" and prone to "heated argument," Burns et al. used the Delphi technique together with a systematic review to ascertain the operative features of effective home-based care [76-77]. These features included-

1. Regular home visits.

2. A higher percentage of contacts at home.

3. Smaller caseloads.

4. Responsibility for both health and social care.

5. Multidisciplinary teamwork.

6. Psychiatrist integration into the team.

However, Wright et al. [80] and Burns et al. [76] are comparing "apples and oranges" by contrasting these methods. The Delphi technique aggregates expert opinion to identify critical components, while DACTS measures fidelity in particular programs. ${ }^{*}$ Both methods can be useful and complementary, and both have their limitations. Whether Burns et al.'s list of critical ingredients is superior to the DACTS elements, however imperfect, is questionable. Moreover, in reality, the Delphi technique is no more rigorous than DACTS, since they both quantify qualitative responses from expert opinion and therefore are disputable.

DACTS is based on research on critical components and outcomes of ACT, as well as expert consensus [53].

*Dr. Gary Bond, personal communication, 2006. 
Meanwhile, the developers of the Delphi method question the appropriateness of such applications, particularly if they are then used to derive performance measures [81]. Most studies conclude that ACT teams likely produce more effective outcomes if their measured fidelity is higher [27]; that is, if they squarely meet more DACTS criteria.

\section{Screening "Heavy Service Users" for Eligibility for Assertive Community Treatment}

Several sites have trialed screening tools to ascertain whether an individual with a mental illness who heavily uses services would be eligible for referral to an ACT or intensive case-management team. Some screening tools are extensive and cumbersome, serving additional administrative or research purposes, but everyday services require a brief practical tool as a prelude or adjunct to in vivo clinical assessment [82]. Abbott et al.'s very brief tool provides differentially weighted scores for prolonged, frequent, or multiple hospitalizations; unstable accommodation; lack of support systems; poor living skills; and physical or substance abuse comorbidities [82]. It also provides scores for inability to benefit from existing services because of lack of insight, motivation, or personal organization. In one Australian service, this tool has been adapted for use with the Life Skills Profile (LSP) [83-84], an empirically well-tested brief functional ability outcome scale that can be rated from a "strengths" perspective. While the LSP has several subscales, the total LSP score can be converted to contribute to the screening tool final score. Several outcome studies of ACT teams have used the LSP [23-25,28]. While the effectiveness of the LSP as a screener has not been demonstrated directly, subsequent quarterly LSP scores (nationally mandated in all Australian mental health services) can establish whether the consumers with the most disabilities are selected for ACT case management, whether the rehabilitation potential judged at screening and initial assessment is realized, and whether these consumers transfer to lower intensity service subsystems when they achieve improved function and stability.

Service administrators or clinical leaders can also use such screening methods for strategic planning to approximate the number of ACT consumer places, staff, and teams required to serve the needs of eligible consumers in a given catchment service or population. Effectiveness and utility of screening tools for determining ACT eligibility require further research.

\section{Qualitative Evaluation of Consumer-Case Manager Relationship}

The quality of relationships with practitioners, such as ACT case managers, is crucial to the perceived experiences of mental health care of individuals with severe mental illness; these perceived experiences, in turn, contribute considerably to whether consumers persist in clinical mental health care. Quantitative and illness-focused studies may miss much of what consumers with severe mental illness value in their relationships with practitioners. Ware et al. applied grounded theory techniques to analyze responses from low-income consumers with severe mental illness regarding what they valued in their relationships with such practitioners [85]. Eight categories of consumer priorities emerged: getting "extra things" (e.g., additional thoughtful acts or services), seeking common ground or interests, feeling known, talking, feeling like "somebody," having the practitioner be available, having the practitioner be flexible (with arrangements, goal setting, etc.), and having opportunities for input into treatment. A further study used thematic analysis of openended interviews and a scale that measured attitude toward professional psychological help to determine older youths' experiences of mental health care [86]. Their concerns centered on three aspects: the relationship with their mental health provider; the providers' professionalism; and the effects of the treatment, including medication.

\section{CONCLUSIONS}

Strong evidence supports the fidelity standardization, efficacy, effectiveness, and cost-effectiveness of the ACT model of case management in psychiatry. ACT case management is currently one of the most effective systematic methods of organizing clinical and functional interventions in psychiatry. However, the ACT model was designed specifically for and works best with consumers with severe mental illness and the greatest functional impairments. So, ACT is not "one size fits all” and other less-intensive case-management models may be effective for individuals with significant mental illnesses but less severe symptoms and disabilities.

Important concerns arise from clinical and evidencebased studies and reviews of case management, including ACT. The more effective case-management systems meet more of the ACT fidelity criteria. In particular, they are less coercive, more collaborative, and do not rely on 
compulsory orders. In addition, they tend to rely on a wider range of interventions than just ensuring medication adherence, including vocational and substance abuse rehabilitation; have evidence-based content and more mobile in vivo interventions; and involve individual and team case management and therapeutic relationships. They may involve consumers as direct service providers and include interdisciplinary work and support structures within the team, which also protect staff from workrelated stress or burnout.

\section{ACKNOWLEDGMENTS}

We thank Professors Gary Bond, Len Stein, and Ron Diamond for expert advice and Ms. Agnes Wroblewski, Ms. Anne Streeter, Ms. Sylvia Hands, and Ms. Vivienne Miller for assisting with manuscript preparation.

This material was unfunded at the time of manuscript preparation.

The authors have been involved both in the delivery and evaluation of case-management systems in mental health services separately and collectively over many years. We do not accept that case management or any other clinical practices can be sustained by belief, but should be applied only according to evidence and married to sound judgment relevant to the context in which they are to be used.

The authors have declared that no competing interests exist.

\section{REFERENCES}

1. Mechanic D. Strategies for integrating public mental health services. Hosp Community Psychiatry. 1991;42(8):797-801. [PMID: 1894253]

2. Rosen A, Teesson M. Does case management work? The evidence and the abuse of evidence-based medicine. Aust N Z J Psychiatry. 2001;35(6):731-46. [PMID: 11990883]

3. Harris M, Bergman HC. Case management for mentally ill patients: Theory and practice. Longhorne (PA): Harwood; 1993.

4. Solomon P. The efficacy of case management services for severely mentally disabled clients. Community Ment Health J. 1992;28(3):163-80. [PMID: 1319304]

5. Mueser KT, Bond GR, Drake RE, Resnick SG. Models of community care for severe mental illness: A review of research on case management. Schizophr Bull. 1998;24(1): 37-74. [PMID: 9502546]
6. Stein LI, Test MA. Alternative to mental hospital treatment. I. Conceptual model, treatment program, and clinical evaluation. Arch Gen Psychiatry. 1980;37(4):392-97. [PMID: 7362425]

7. Hoult J, Rosen A, Reynolds I. Community oriented treatment compared to psychiatric hospital orientated treatment. Soc Sci Med. 1984;18(11):1005-10. [PMID: 6740335]

8. Chambless DL, Hollon SD. Defining empirically supported therapies. J Consult Clin Psychol. 1998;66(1):7-18. [PMID: 9489259]

9. Stein LI. Perspective: On the abolishment of the case manager. Health Aff. 1992;11(3):172-77.

10. Marshall M, Lockwood A. Assertive community treatment for people with severe mental disorders. Cochrane Database Syst Rev. 2000;(2):CD001089. [PMID: 10796415]

11. Stein LI, Santos AB. Assertive community treatment of persons with severe mental illness. New York (NY): Norton; 1998.

12. Allness DJ, Knoedler WH. The PACT model of community-based treatment for persons with severe and persistent mental illness. A manual for PACT start-up. Arlington (VA): National Alliance for the Mentally Ill; 1998.

13. U.S. Substance Abuse and Mental Health Services Administration. Assertive community treatment: Implementation resource kit. Washington (DC): U.S. Department of Health and Human Services, Substance Abuse and Mental Health Services Administration, Center for Mental Health Services; 2003.

14. Rapp CA, Goscha RJ. What are the common features of evidence-based practices. In: Drake RE, Merrens MR, Lynde DW, editors. Evidence-based mental health practice. A textbook. New York (NY): W. W. Norton; 2005. p. 189-215.

15. Teague GB, Bond GR, Drake RE. Program fidelity in assertive community treatment: Development and use of a measure. Am J Orthopsychiatry. 1998;68(2):216-32. [PMID: 9589760]

16. Salyers MP, Bond GR, Teague GB, Cox JF, Smith ME, Hicks ML, Koop JI. Is it ACT yet? Real-world examples of evaluating the degree of implementation for assertive community treatment. J Behav Health Serv Res. 2003;30(3): 304-20. [PMID: 12875098]

17. Bond GR, Drake RE, Mueser KT, Latimer E. Assertive community treatment for people with severe mental illness: Critical ingredients and impact on patients. Dis Manage Health Outcomes. 2001;9(3):141-59.

18. Solomon P. Case management. In: Corrigan PW, Mueser KT, Bond GR, Drake RE, Solomon P, editors. The comprehensive textbook of psychiatric rehabilitation. New York (NY): Guilford Press. In press 2007.

19. Dixon L. Assertive community treatment: Twenty-five years of gold. Psychiatr Serv. 2000;51(6):759-65. [PMID: 10828107] 
20. The Lewin Group. Assertive community treatment literature review. Washington (DC): Health Care and Financing Administration (HCFA) and Substance Abuse and Mental Health Services Administration (SAMHSA); 2000.

21. Bachrach LL. Overview: Model programs for chronic mental patients. Am J Psychiatry. 1980;137(9):1023-31. [PMID: 7425150]

22. Morse G, McKasson M. Assertive community treatment. In: Drake RE, Merrens MR, Lynde DW, editors. Evidencebased mental health practice: A textbook. New York (NY): Norton; 2005. p. 317-47.

23. Teesson M, Hambridge J. Mobile community treatment in inner city and suburban Sydney. Psychiatr Q. 1992;63(2): 119-27. [PMID: 1488457]

24. Teesson M. Evaluation of mental health service delivery in an inner city area [thesis]. Sydney (Australia): University of New South Wales; 1995.

25. Hambridge JA, Rosen A. Assertive community treatment for the seriously mentally ill in suburban Sydney: A programme description and evaluation. Aust N Z J Psychiatry. 1994;28(3):438-45. [PMID: 7893238]

26. Morgan V, Korten A, Jablensky A. Modifiable risk factors for hospitalization among people with psychosis: Evidence from the National Study of Low Prevalence (Psychotic) Disorders. Aust N Z J Psychiatry. 2006;40(8):683-90. [PMID: 16866764]

27. Latimer EA. Economic impacts of assertive community treatment: A review of the literature. Can J Psychiatry. 1999; 44(5):443-54. [PMID: 10389605]

28. Issakidis C, Sanderson K, Teesson M, Johnston S, Buhrich $\mathrm{N}$. Intensive case management in Australia: A randomized controlled trial. Acta Psychiatr Scand. 1999;99(5):360-67. [PMID: 10353452]

29. Burns T, Creed F, Fahy T, Thompson S, Tyrer P, White I. Intensive versus standard case management for severe psychotic illness: A randomised trial. UK 700 Group. Lancet. 1999;353(9171):2185-89. [PMID: 10392982]

30. McFarlane WR. Multifamily groups in the treatment of severe psychiatric disorders. New York (NY): Guilford Press; 2002.

31. Rosen A, Newton L, Barfoot K. Evidence based community alternatives to institutional psychiatric care. Med Today. 2003;4(9):90-95.

32. Bond GR, Salyers MP, Rollins AL, Moser LL. Future developments in assertive community treatment. In: Mulder L, Kroon H, editors. Assertive community treatments. Nijmegen (the Netherlands): Cure and Care Publishers; 2005. p. 205-41.

33. Ryan CS, Sherman PS, Bogart LM. Patterns of services and consumer outcome in an intensive case management program. J Consult Clin Psychol. 1997;65(3):485-93. [PMID: 9170772]
34. Angell B. Measuring strategies used by mental health providers to encourage medication adherence. J Behav Health Serv Res. 2006;33(1):53-72. [PMID: 16636908]

35. Pratt SI, Mueser KT, Driscoll M, Wolfe R, Bartels SJ. Medication nonadherence in older people with serious mental illness: Prevalence and correlates. Psychiatr Rehabil J. 2006; 29(4):299-310. [PMID: 16689041]

36. Fenton WS, Blyler CR, Heinssen RK. Determinants of medication compliance in schizophrenia: Empirical and clinical findings. Schizophr Bull. 1997;23(4):637-51. [PMID: 9366000]

37. Drake RE, McHugo GJ, Clark RE, Teague GB, Xie H, Miles K, Ackerson TH. Assertive community treatment for persons with co-occurring severe mental illness and substance abuse disorder: A clinical trial. Am J Orthopsychiatry. 1998;68(2):201-15. [PMID: 9589759]

38. Edwards J, Maude D, McGorry PD, Harrigan SM, Cocks JT. Prolonged recovery in first-episode psychosis. $\mathrm{Br} \mathrm{J}$ Psychiatry Suppl. 1998;172(33):107-16. [PMID: 9764136]

39. Lehman AF, Dixon LB, Kernan E, DeForge BR, Postrado LT. A randomized trial of assertive community treatment for homeless persons with severe mental illness. Arch Gen Psychiatry. 1997;54(11):1038-43. [PMID: 936661]

40. Thornicroft G, Breakey WR. The COSTAR programme. 1: Improving social networks of the long-term mentally ill. Br J Psychiatry. 1991;159:245-49. [PMID: 1773241]

41. Test MA, Allness DJ, Knoedler WH. Impact of 7 years of Assertive Community Treatment. In: Proceedings summary of the American Psychiatric Association Institute on Psychiatric Services; 1995 Oct 6-10; Boston, MA. Arlington (VA): APA; 1995.

42. McFarlane WR, Test MA, Drake RE, Bond G. The way to work: Assertive community treatments as vocational rehabilitation. Boston (MA): Psychiatric Services Institute; 1995.

43. Drake RE, Becker DR. The individual placement and support model of supported employment. Psychiatr Serv. 1996; 47(5):473-75. [PMID: 8740486]

44. Bond GR, Drake RE, Mueser KT, Becker DR. An update on supported employment for people with severe mental illness. Psychiatr Serv. 1997;48(3):335-46. [PMID: 9057235]

45. Furlong M, McCoy ML, Dincin J, Clay R, McClory K, Pavick D. Jobs for people with the most severe psychiatric disorders: Thresholds Bridge North pilot. Psychiatr Rehabil J. 2002;26(1):13-22. [PMID: 12171278]

46. Gold PB, Meisler N, Santos AB, Carnemolla MA, Williams $\mathrm{OH}$, Kelleher J. Randomised trial of supported employment integrated with assertive community treatment for rural adults with severe mental illness. Schizophr Bull. 2006;32:378-95.

47. Bond GR. Supported employment: Evidence for an evidencebased practice. Psychiatr Rehabil J. 2004;27(4):345-59. [PMID: 15222147] 
48. Goldman HH, Morrissey JP, Ridgely MS. Form and function of mental health authorities at Robert Wood Johnson Foundation Program sites: Preliminary observations. Hosp Community Psychiatry. 1990;41(11):1222-30. [PMID: 2249801

49. Rosenheck R, Neale M, Leaf P, Milstein R, Frisman L. Multisite experimental cost study of intensive psychiatric community care. Schizophr Bull. 1995;21(1):129-40. [PMID: 7770734]

50. Thornicroft G, Strathdee G, Phelan M, Holloway F, Wykes T, Dunn G, McCrone P, Leese M, Johnson S, Szmukler G. Rationale and design. PRiSM Psychosis Study. 1. Br J Psychiatry. 1998;173:363-70. [PMID: 9926051]

51. Thornicroft G, Wykes T, Holloway F, Johnson S, Szmukler G. From efficacy to effectiveness in community mental health services. PRiSM Psychosis Study. 10. Br J Psychiatry. 1998;173:423-27. [PMID: 9926060]

52. Wykes T, Leese M, Taylor R, Phelan M. Effects of community services on disability and symptoms. PRiSM Psychosis Study. 4. Br J Psychiatry. 1998;173:385-90. [PMID: 9926054]

53. Phillips SD, Burns BJ, Edgar ER, Mueser KT, Linkins KW, Rosenheck RA, Drake RE, McDonel Herr EC. Moving assertive community treatment into standard practice. Psychiatr Serv. 2001;52(6):771-79. [PMID: 11376224]

54. Gomory T. A critique of the effectiveness of assertive community treatment. Psychiatr Serv. 2001;52(10):1394-95. [PMID: 11585962]

55. Gomory T. Effectiveness of assertive community treatment. Psychiatr Serv. 2002;53(11):103. [PMID: 11773664$]$

56. Test MA, Stein LI. In reply: A critique of the effectiveness of assertive community treatment. Psychiatr Serv. 2001;52(10): 1396.

57. Moser LL. Assertive community treatment teams' use of restrictive practices. In: Quarterly Meeting of the MacArthur Research Network on Mandated Community Treatment; 2006 May 4; Boston, MA. Charlottesville (VA): MacArthur Research Network; 2006.

58. Neale MS, Rosenheck RA. Therapeutic limit setting in an assertive community treatment program. Psychiatr Serv. 2000;51(4):499-505. [PMID: 10737826]

59. Rosenheck RA, Neale M. Intersite variation in the impact of intensive psychiatric community care on hospital use. Am J Orthopsychiatry. 1998;68(2):191-200. [PMID: 9589758]

60. Salyers MP, Masterton TW, Fekete DM, Picone JJ, Bond GR. Transferring clients from intensive case management: Impact on client functioning. Am J Orthopsychiatry. 1998; 68(2):233-45. [PMID: 9589761]

61. McGrew JH, Wilson R, Bond GR. Client perspectives on critical ingredients of assertive community treatment. Psychiatr Rehabil J. 1996;19:13-21.

62. Diamond RJ. Coercion and tenacious treatment in the community: Applications to the real world. In: Dennis D,
Monahan J, editors. Coercion and aggressive community treatment: A new frontier in mental health law. New York (NY): Plenum Press; 1996. p. 51-72.

63. Preston NJ, Kisely S, Xiao J. Assessing the outcome of compulsory psychiatric treatment in the community: Epidemiological study in Western Australia. BMJ. 2002; 324(7348):1244. [PMID: 12028977$]$

64. Boyer SL, Bond GR. Does assertive community treatment reduce burnout? A comparison with traditional case management. Ment Health Res Serv. 1999;1(1):31-45.

65. Onyett S, Pillinger T, Muijen M. Making community mental health teams work: CMHTs and the people who work in them. London (England): Sainsbury Centre for Mental Health; 1995.

66. Rosen A, Callaly T. Interdisciplinary teamwork and leadership: Issues for psychiatrists. Australas Psychiatry. 2005; 13(3):234-40. [PMID: 16174195]

67. Rapp CA, Goscha RJ. The principles of effective case management of mental health services. Psychiatr Rehabil J. 2004;27(4):319-33. [PMID: 15222145]

68. Killaspy H, Bebbington P, Blizard R, Johnson S, Nolan F, Pilling S, King M. The REACT study: Randomised evaluation of assertive community treatment in north London. BMJ. 2006;332(7545):815-20. [PMID: 16543298]

69. Carter J. Learning together: Education and training partnerships in mental health strategy. Canberra (Australia): Commonwealth Department of Health and Aged Care; 1999.

70. Miller V. "I took the road less traveled by . . . and that has made all the difference.” Pathways towards mental health service integration. In: Proceedings of The Mental Health Services (The MHS) 5th Annual Conference of Australia and New Zealand; 1995 Sep 4-7; Auckland, New Zealand. New South Wales (Australia): The MHS Conference; 1995. p. 38-48.

71. Ashcroft L, Johnson E, Zeeb M. Mental health recovery. Peer employment training workbook, Module 2. Phoenix (AZ): Meta Services, Inc; 2004. p. 1-17.

72. Ashcraft L, Anthony WA. A story of transformation: An agency fully embraces recovery. Behav Healthc Tomorrow. 2005;14(2):12-21. [PMID: 15887602$]$

73. Lefley HP. Advocacy, self-help and consumer-operated services. In: Tasman A, Kay J, Lieberman JA, editors. Psychiatry. Philadelphia (PA): W. B. Saunders; 1997. p. 1770-80.

74. Davidson L, Chinman M, Sells D, Rowe M. Peer support among adults with serious mental illness: A report from the field. Schizophr Bull. 2006;32(3):443-50. [PMID: 16461576$]$

75. Krupa T, Eastabrook S, Hern L, Lee D, North R, Percy K, Von Briesen B, Wing G. How do people who receive assertive community treatment experience this service? Psychiatr Rehabil J. 2005;29(1):18-24. [PMID: 16075693] 
76. Burns T, Fioretti A, Holloway F, Malm U, Rössler W. Case management and assertive community treatment in Europe. Psychiatr Serv. 2001;52(5):631-36. [PMID: 11331797]

77. Burns T, Catty J, Wright C. Deconstructing home-based care for mental illness: Can one identify the effective ingredients? Acta Psychiatr Scand Suppl. 2006;113(429):33-35.

78. Marshall M, Bond G, Stein LI, Shepherd G, McGrew J, Hoult J, Rosen A, Huxley P, Diamond RJ, Warner R, Olsen M, Latimer E, Goering P, Craig TK, Meisler N, Test MA. PRiSM Psychosis Study. Design limitations, questionable conclusions. Br J Psychiatry. 1999;175:501-3. [PMID: 10789344$]$

79. Ziguras SJ, Stuart GW, Jackson AC. Assessing the evidence on case management. Br J Psychiatry. 2002;181:17-21. [PMID: 12091258]

80. Wright C, Catty J, Watt H, Burns T. A systematic review of home treatment services-Classification and sustainability. Soc Psychiatry Psychiatr Epidemiol. 2004;39(10):789-96. [PMID: 15669659]

81. Burnam A. Commentary: Selecting performance measures by consensus: An appropriate extension of the Delphi method? Psychiatr Serv. 2005;56(12):1583.

82. Abbott S, Smith S, Clarke R, Curson C, De Souza Gomes J, Heslop K, Trainer E, Yellowlees P. Who is a heavy ser- vice user? Preliminary development of a screening instrument for prospective consumers of a mobile intensive treatment team. Aust N Z J Psychiatry. 1997;31(5):744-50. [PMID: 9400881]

83. Rosen A, Hadzi-Pavlovic D, Parker G. The Life Skills Profile: A measure assessing function and disability in schizophrenia. Schizophr Bull. 1989;15(2):325-37. [PMID: 2749191]

84. Parker G, Rosen A, Trauer T, Hadzi-Pavlovic D. Disability associated with mood states and comparator conditions: Application of the Life Skills Profile measure of disability. Bipolar Disord. 2007;9(1-2):11-15. [PMID: 17391345]

85. Ware NC, Tugenberg T, Dickey B. Practitioner relationships and quality of care for low-income persons with serious mental illness. Psychiatr Serv. 2004;55(5):555-59.

[PMID: 15128964]

86. Lee BR, Munson MR, Ware NC, Ollie MT, Scott LD Jr, McMillen JC. Experiences of and attitudes toward mental health services among older youths in foster care. Psychiatr Serv. 2006;57(4):487-92. [PMID: 16603743]

Submitted for publication September 7, 2006. Accepted in revised form September 14, 2007. 